Research Paper:

\title{
The Relationship Between Perfectionism, Early Mal- adaptive Schemas, Attachment Styles, and Body Image Concern by the Mediating Role of Self-esteem in Cosmet- ic Surgery Applicants
}

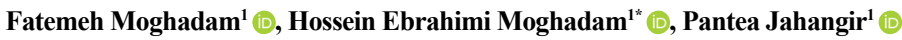

1. Department of Psychology, Rudehen Branch, Islamic Azad University, Rudehen, Iran.

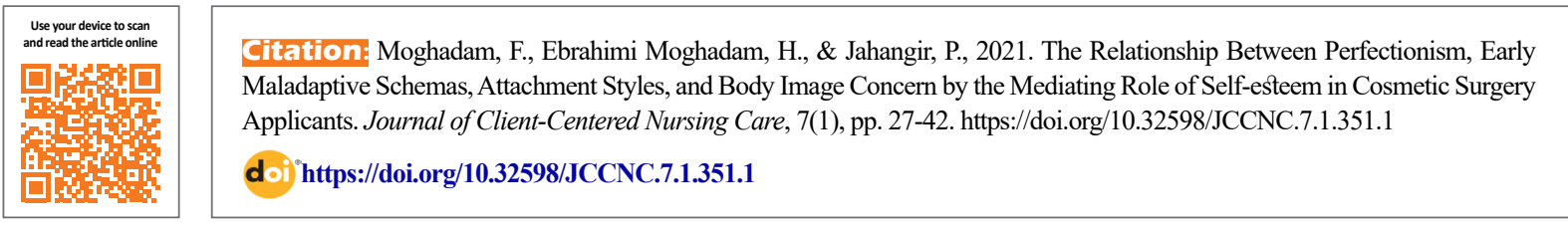

\section{(1) (3)}

Article info:

Received: 11 May 2020

Accepted: 02 Oct 2020

Published: 01 Feb 2021
Keywords:

Body image, Selfesteem, Perfectionism, Cosmetic Surgery, Attachment

\begin{abstract}
A B S T R A C T
Background: Psychological characteristics could significantly impact applications for cosmetic surgery as well as precognition and satisfaction with surgery. The present study aimed to investigate the relationship between perfectionism, early maladaptive schemas, attachment styles, and body image concern by the mediating role of self-esteem in cosmetic surgery applicants.

Methods: This was a predictive correlational study. The statistical population of the study included all female applicants for cosmetic surgery referring to cosmetic surgery centers in Tehran City, Iran, in 2020. A sample size of 400 women was selected based on Klein's model. The required data were collected by Rosenberg Self-Esteem Scale (RSES), Multidimensional Perfectionism Scale (MPS), Young Schema Questionnaire (YSQ-S3), Adult Attachment Scale (AAS), and Body Image Concern Inventory (BICI), and analyzed using Pearson correlation coefficient and structural equations in SPSS and AMOS v. 24.

Results: The obtained results signified a significant relationship between perfectionism, early maladaptive schemas, attachment styles, self-esteem, and body image concerns $(\mathrm{P}<0.01)$. Furthermore, the modified model presented a good fit (The Root Mean Square Error of Approximation (RMSEA) $=0.061, \mathrm{GFI}=0.989, \mathrm{IFI}=0.987, \mathrm{P}<0.05$ ); the indirect paths of perfectionism, early maladaptive schema, and attachment styles through self-esteem were also significant.
\end{abstract}

Conclusion: The evaluated model indicated a good fit; thus, it can play an essential role in recognizing the factors affecting the body image concerns of female cosmetic surgery applicants.

\section{* Corresponding Author:}

Hossein Ebrahimi Moghadam, PhD.

Address: Department of Psychology, Rudehen Branch, Islamic Azad University, Rudehen, Iran.

Tel: +98 (21) 76505891

E-mail: ebrahimimoghadamh@gmail.com 


\section{Highlights}

- There was a significant relationship between perfectionism, early maladaptive schemas, and body image concerns in cosmetic surgery applicants.

- There was a significant relationship between attachment styles, self-esteem, and body image concerns in cosmetic surgery applicants.

- The indirect paths of perfectionism, early maladaptive schema, and attachment styles through self-esteem were significant.

\section{Plain Language Summary}

Cosmetic surgery is among the most popular surgeries worldwide, especially in Iran. This study investigated the association between perfectionism, early maladaptive schemas, attachment styles, and body image concerns through the mediation of self-esteem in cosmetic surgery applicants. The relevant results suggested that the modified model had a good fit and the indirect paths of perfectionism, early maladaptive schema, and attachment styles through self-esteem were also significant. The evaluated model had a good fit and can play an important role in recognizing the factors affecting the body image concerns of female cosmetic surgery applicants.

\section{Introduction}

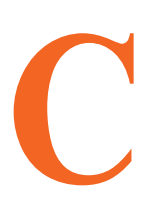

osmetic surgery is among the most frequent surgeries globally and the number of applicants is increasing day by day. The rate of cosmetic surgery in Iran is 7 times higher than in European countries and $90 \%$ of cosmetic surgery in Iran concerns rhinoplasty (Rounagh Sheshkelani et al. 2018). In the United States, the number of individuals who underwent cosmetic surgery in 2000 was approximately 1.3 million; an increase of about 198\%, compared to 1992 (E’temadifard \& Amani 2013).

Attractiveness and beauty are popular traits for all individuals in all societies (Lazuka et al. 2020); thus, it is not surprising that thousands of individuals undergo cosmetic surgery annually to improve their body and appearance (David, 2006; quoted by Shirmohammadi, Hosseini \& Amiri 2020). Cosmetic surgery is used to improve appearance (Sun et al. 2020), a specialty that restores, maintains, or improves the physical appearance of an individual through surgical and medical techniques (Swami et al. 2009). Therefore, with the intention of beautification, plastic surgery emerged with modernity; by the acceptance of the majority, it became one of the social norms and appeared as a daily concern of society, especially in young women (Enayat \& Anbari Roozbehani 2017). Various factors can be influential in the tendency and demand for cosmetic surgery, especially in women and one of such factors is body image concern (Gillen \& Markey 2020; Yektatalab et al. 2015). Dissatisfaction and concern about body image refer to a negative perception of physical appearance (Barnes et al. 2020) and denotes the difference between the perception of the body and the ideal body (Karazsia, Murnen \& Tylka 2017). This concern is associated with numerous problems, such as eating disorders (Troncone et al. 2020) and irregular eating (Carrard, Rothen \& Rodgers 2020). Several variables can predict this concern, one of which is perfectionism (Jamshidi \& Hashemi 2019). Perfectionism is the constant tendency of an individual to adopt complete and unattainable standards and strive to achieve them (Hewitt et al. 2020).

Perfectionism refers to self-destructive thoughts and behaviors that aim to achieve extreme and unrealistic goals (Hejazi \& Hashemi 2020). Perfectionism is among the personality and motivational traits of an individual that influences their behavior. Besides, it is characterized by features, such as striving for perfection and setting very extreme criteria in performance along with a tendency to the critical evaluation of behavior. In other words, perfectionism is defined as a combination of excessively high personal standards and critical self-evaluation (Curran \& Hill 2019). In addition to perfectionism, a predictor of the demand for non-medical and non-essential cosmetic surgery is early maladaptive schemas (Nilforoshan, Navidian \& Shamhammdi 2015), i.e. also related to perfectionism (Salmanpour et al. 2014). Early maladaptive schemas are the emotional and cognitive patterns of self-harm, i.e. formed in the mind at the beginning 
of development (Koppers et al. 2020) and are repeated throughout life (Janovsky et al. 2020). Besides, when the early maladaptive schema states are activated, they can affect an individual's perception of reality and cognitive processing (Borges \& Dell'Aglio 2020). According to Young, Klosko and Weishaar (2003), early maladaptive schemas are emotional and cognitive patterns of selfharm, i.e. formed in the mind at the beginning of growth and development; they are repeated throughout life and maladaptive and problematic behaviors are responses to these schemas (Meneguzzo et al. 2020).

Such situations can also be created by insecure attachment styles; accordingly, if individuals fail to take responsive and accessible care during the early years of life, they might experience more problems in the future and are more likely to tend towards inconsistent behaviors (Henschel, Nandrino \& Doba 2020). Attachment styles refer to certain internal patterns of attachment that determine the pattern of individuals' behavioral responses to separation from an attachment image and reconnection with these images. These internal models provide a secure basis for the individual and enable them to regulate emotions in a relatively independent and practical manner. Thus, these attachment styles are formed mainly based on the individual's experiences with primary care, remain relatively stable throughout life, and affect their social interactions (Fuchshuber et al. 2019). Perfectionism (Saravani \& Shirazi 2018), early maladaptive schemas (Salehi, Rajabi \& Dehghani 2019), and attachment styles (Szalai et al. 2017; Homan et al. 2018) are related to concerns about body image. Furthermore, self-esteem can be related to predictor variables and affect body image concerns. Accordingly, there was a relationship between self-esteem and dysfunctional attitudes, and body image concerns in rhinoplasty applicants (Ghanbari Nejad Esfeghansari \& Zarbakhsh Bahri 2015).

Therefore, self-esteem can be a suitable mediating variable in the research model. Self-esteem is a psychological phenomenon (Rosenthal et al. 2020; Dehghan et al. 2015 ) that presents a decisive effect on the emotional and cognitive dimensions of individuals (Wells et al. 2020); its function is effective and essential in coping with life stressors (Tam, Benotsch \& Li 2020). Self-esteem is the most definite factor in the process of mental development. Besides, no matter how much an individual fails to gain self-esteem, he/she is subject to anxiety, psychological instability, self-doubt, and a feeling of inadequacy in life (Nasiri, Nasiri \& Bakhshi Pour Rudsari 2014; Harorani et al. 2018). Based on the evidence, the importance of influencing variables, such as self-esteem, perfectionism, early maladaptive schemas, and attachment styles on body image concerns are inferred. However, this evidence is first and foremost preliminary. Additionally, they lack the necessary coherence and coordination to conclude. Moreover, the set of these factors has not been studied together and in interaction with each other. Therefore, in the present study, these 3 categories of factors were considered together and their direct and indirect relationships with body image concern were examined. Therefore, this study aimed to examine the effects of self-esteem on the relationship between perfectionism, early maladaptive schemas, attachment styles, and body image concerns in cosmetic surgery applicants.

\section{Materials and Methods}

This was a predictive correlational study. The statistical population of the study included all female applicants for cosmetic surgery referring to cosmetic surgery centers in Tehran City, Iran, in 2020. There is no general agreement on the sample size required for factor analysis and structural equation; however, Kline (2016) believes that 10 or 20 samples are required per variable, and the minimum sample size of 200 is defendable. In this study, for further generalizability of the results and considering the odds of losing some questionnaires, a sample size of 400 subjects was selected.

The following instruments were used in the current study to collect the necessary data:

Rosenberg Self-Esteem Scale (RSES): This scale was developed by Rosenberg (1989). It consists of 10 questions in which questions $1,2,3,4$, and 5 are scored on a 4-point Likert-type scale (strongly agree $=3$; strongly disagree $=0$ ). Questions 6, 7, 8, 9, and 10 are scored in reverse. The minimum total score is 0 and the maximum is 30, with higher scores representing higher self-esteem (García et al. 2019). In one study, Cronbach's alpha coefficient was used to investigate the internal consistency of the scale. Moreover, its convergent and differential validity was evaluated using the Revised NEO Personality Inventory (NEO-PI-R) (Costa \& McCrae 2008) and Connor-Davidson Resilience Scale (Conner \& Davidson 2003). Subsequently, the obtained correlation coefficient was -0.81 for neuroticism and 0.82 concerning resilience, being significant at the 0.01 level. These data indicated the convergent validity with resilience and differential validity with the personality trait of neuroticism (Vaghar Hasanpur, Jalali \& Tayebli 2020). Cronbach's alpha coefficient was also used to evaluate the reliability of the scale, which yielded a coefficient of 0.85 (Lannoy et al. 2020). In the present study, Cronbach's alpha coefficient of the scale was calculated to be 0.85 . 
Multidimensional Perfectionism Scale (MPS): This scale was developed by Hewitt and Flett (1991) and includes 30 questions and 3 subscales of self-oriented perfectionism (questions 1, 3, 5, 7, 9, 11, 13, 14, 15, $21,23,25,26,28, \& 30)$; other-oriented perfectionism (questions 4, 8, 10, 12, 16, 17, 18, 19, 20, 27, \& 29); and socially prescribed perfectionism (questions 2, 6, 22, and 24) (Hewitt \& Flett 1991). The scale is scored on a 7-point Likert-type scale (from strongly disagree $=1$ to strongly agree $=7$ ). The self-oriented score ranges from 15 to 105 . The other-oriented point is 10 to 70 , and the socially prescribed one is between 4 and 28 . The overall scale score is between 30 and 210 (Chen et al. 2019). The Cronbach's alpha coefficient of the questionnaire was calculated to range between 0.70 and 0.75 (Zeifman, Antony \& Kuo 2020). In Iran, the Cronbach's alpha coefficient of the questionnaire was measured as 0.63 for self-oriented, 0.75 for other-oriented, and 0.69 for socially prescribed perfectionism (Sadeghi et al. 2019). In the present study, Cronbach's alpha coefficient of the scale was computed as 0.86 .

Young Schema Questionnaire-Short Form version 3 (YSQ-S3): This questionnaire was developed by Young and contains 75 items in 5 main areas, including disconnection and rejection, autonomy and dysfunction, impaired limitations, self-direction, hypervigilance, and inhibition (Young \& Brown 2005). It is scored based on a 6-point Likert-type scale, as follows: absolutely false: 1 point, almost false: 2 points, more true than false: 3 points, slightly true: 4 points, almost true: 5 points, and absolutely true: 6 points. The overall scale score is between 75 and 450. Cronbach's alpha coefficient of the questionnaire ranged from 0.72 to 0.86 (Cudo et al. 2020). In studies in Iran, Cronbach's alpha coefficient was used to assess the reliability of the questionnaire. In a study in Iran, the Cronbach's alpha coefficient of the total scale was computed as 0.96 (Borji et al. 2019). In another study, Cronbach's alpha coefficient of the components ranged from 0.89 to 0.96 (Shabani Khadio \& Ahmadian 2019). In the present study, Cronbach's alpha coefficient of the scale was measured as 0.91 .

Adult Attachment Scale (AAS): This scale was developed by Collins and Read in 1990. It has 18 questions to measure 3 sub-styles; secure attachment, anxious ambivalent insecure attachment, and avoidant insecure attachment (Collins \& Read 1990). The questions are scored on a 5-point Likert-type scale, ranging from strongly disagree $=1$ to strongly agree $=5$. A higher score in each subscale reflects greater feelings of the ease with closeness and intimacy, more comfort with depending on others, and a belief that others will be accessible when needed, or greater concern about being rejected or unloved. The relevant Cronbach's alpha coefficients were reported to be 0.72 for secure attachment, 0.67 for anxious ambivalent insecure attachment, and 0.75 for avoidant insecure attachment (Gouin \& McNeill 2019). In Iran, the Cronbach's alpha coefficient of this scale was computed as 0.89 for secure attachment, 0.77 for anxious ambivalent insecure attachment, and 0.81 for avoidant insecure attachment (Rezaei Jamaloui, Hassani \& Normohamadi Najafabadi 2019). In the present study, Cronbach's alpha coefficient was measured to be 0.70 .

Body Image Concern Inventory (BICI): This inventory was developed by Littleton, Axsom and Pury (2005). BICI contains 19 questions and is scored on a 5-point Likert-type scale (from never $=1$ to always $=5$ ). The overall score range of the inventory is between 19 and 95 . The related Cronbach's alpha coefficient was calculated to be 0.92 (Thompson \& Bardone-Cone 2019). In Iran, Cronbach's alpha coefficient was measured as 0.93 for all questions (Askari \& Ramezani Badr 2015). In another study, Cronbach's alpha coefficient was calculated to be 0.78 . Moreover, its convergent validity was evaluated by the Eysenck Aggression Questionnaire and the correlation coefficient was equal to 0.23 , i.e. significant at the level of 0.01 (Heidari et al. 2016). In the present study, Cronbach's alpha coefficient was computed to be 0.76 .

The field study was conducted during the outbreak of Coronavirus (Covid-19); thus, it was impossible to perform paper-pencil questionnaires on the study sample. Accordingly, the online implementation method was employed in this study by the convenience sampling method. The inclusion criteria were female gender, providing informed consent to participate in the study, being a cosmetic surgery applicant during the last 6 months, having no physical and mental illnesses, and no history of previous cosmetic surgery. Subsequently, the questionnaires were designed in Google Drive; by referring to the available centers, its link was provided to interested physicians to send to the applicants for cosmetic surgery. After collecting the data, 440 responses were received and a total of 400 questionnaires were analyzed following the elimination of incomplete questionnaires.

The collected data were analyzed at descriptive and inferential levels. At the descriptive level, mean and standard deviation were used to describe the research variables. At the inferential level, Pearson correlation coefficient and structural equation modeling were applied to investigate the relationships between the study variables. Data analyses were conducted in SPSS V. 24 and AMOS V. 24. 


\section{Results}

The subjects included 400 women applying for cosmetic surgery. The Mean \pm SD age of the research subjects was $30.72 \pm 4.12$. Table 1 presents the demographic characteristics of the study subjects.

Table 2 lists the descriptive and normal indicators of perfectionism, early maladaptive schemas, attachment styles, body image concerns, and self-esteem. The significant levels of Kolmogorov-Smirnov statistics were $>0.05$; thus, the scores provided a normal distribution. Moreover, the results of the skewness and kurtosis tests for the normal distribution of scores suggested that the levels of skewness and kurtosis of the research variables fell in the acceptable range (-2 to 2). Therefore, the distribution of all research variables was normal. Accordingly, the Pearson correlation coefficient and structural equations could be used; the results of these statistical tests were reliable. The initial model details are presented in Figure 1. The total score of initial maladaptive schemas $(\mathrm{P}<0.01, \mathrm{r}=0.610)$, anxiety insecure attachment $(\mathrm{P}<0.01, \mathrm{r}=0.874)$, avoidant insecure attach- ment $(\mathrm{P}<0.01, \mathrm{r}=0.880)$, and body image concern. Safe attachment $(\mathrm{P}<0.01, \mathrm{r}=-0.778)$ and self-esteem $(\mathrm{P}<0.01$, $\mathrm{r}=-0.658)$ provided a negative and significant relationship with body image concern. As per Table 3, the correlation between the variables was significant. Therefore, it was possible to study the research model. The results of direct and indirect coefficients and model fit are as indicated as follows.

According to Table 4, only self-oriented perfectionism ( $\beta=0.829, \mathrm{P}=0.001)$ was significant on body image concern. Among the early maladaptive schemas, only the domains of disconnection and rejection $(\beta=0.196$, $\mathrm{P}=0.014)$ and hypervigilance $(\beta=0.232, \mathrm{P}=0.025)$ were significant concerning body image concern. Additionally, among single attachment styles, avoidant type $(\beta=0.458, P=0.001)$ was significant in respecting body image concern. The effects of secure attachment and anxious attachment styles on body image concern were not significant. To investigate the indirect relationship of the proposed model, the Bootstrap method was used in the computer code by Preacher and Hayes (2004). The

Table 1. Demographic characteristics of the study samples

\begin{tabular}{|c|c|c|}
\hline \multicolumn{2}{|c|}{ Demographic Variables } & \multirow{2}{*}{$\begin{array}{c}\text { No. (\%) } \\
104(26.00)\end{array}$} \\
\hline \multirow{6}{*}{ Educational level } & High school & \\
\hline & Associate degree & $95(23.75)$ \\
\hline & BA & 73 (18.25) \\
\hline & MA & $98(2450)$ \\
\hline & $\mathrm{PhD}$ & $30(7.50)$ \\
\hline & Total & $400(100)$ \\
\hline \multirow{5}{*}{ Occupation } & Housewife & $313(78.25)$ \\
\hline & Employee & $49(12.25)$ \\
\hline & & \\
\hline & Part-time & $38(9.50)$ \\
\hline & Total & $400(100)$ \\
\hline \multirow{5}{*}{ Type of surgery } & Nose & $288(72.00)$ \\
\hline & Chin & $58(14.50)$ \\
\hline & Cheek & $17(4.25)$ \\
\hline & Lip & $37(9.25)$ \\
\hline & Total & $400(100)$ \\
\hline \multicolumn{2}{|c|}{ Age $(y)$, Mean $\pm S D$} & $30.72 \pm 4.12$ \\
\hline
\end{tabular}

Client- Centered Nursing Care 
Table 2. Descriptive indicators and the normality of research variables $(\mathrm{N}=440)$

\begin{tabular}{|c|c|c|c|c|c|c|c|}
\hline Variables & Min. & Max. & Mean $\pm S D$ & Skewness & Kurtosis & KS Statistics & Probability Value \\
\hline Self-oriented perfectionism & 16 & 63 & $35.53 \pm 14.14$ & 0.418 & -1.080 & 0.114 & 0.200 \\
\hline Other-oriented perfectionism & 17 & 64 & $35.08 \pm 14.87$ & 0.715 & -0.849 & 0.187 & 0.059 \\
\hline Society-oriented perfectionism & 8 & 26 & $17.64 \pm 6.16$ & -0.045 & -1.809 & 0.281 & 0.051 \\
\hline $\begin{array}{l}\text { Disconnection and rejection } \\
\text { schema }\end{array}$ & 74 & 124 & $104.56 \pm 15.80$ & -0.098 & -1.583 & 0.130 & 0.200 \\
\hline $\begin{array}{l}\text { Autonomy and dysfunction } \\
\text { schema }\end{array}$ & 58 & 96 & $78.29 \pm 12.85$ & -0.315 & -1.728 & 0.184 & 0.061 \\
\hline Impaired Limits Schema & 27 & 48 & $39.77 \pm 6.94$ & -0.198 & -1.684 & 0.116 & 0.200 \\
\hline Self-direction schema & 30 & 48 & $39.38 \pm 5.93$ & -0.244 & -1.701 & 0.151 & 0.078 \\
\hline Extreme hypervigilance Schema & 29 & 47 & $39.82 \pm 5.72$ & -0.363 & -1.773 & 0.140 & 0.107 \\
\hline $\begin{array}{l}\text { Total score of early maladaptive } \\
\text { schemas }\end{array}$ & 220 & 361 & $301.81 \pm 45.61$ & -0.651 & -0.788 & 0.186 & 0.058 \\
\hline Secure attachment & 8 & 25 & $14.70 \pm 5.90$ & -0.514 & -1.535 & 0.174 & 0.061 \\
\hline Anxious insecure attachment & 8 & 25 & $17.35 \pm 5.76$ & -0.348 & -1.590 & 0.196 & 0.112 \\
\hline Avoidant insecure attachment & 8 & 24 & $17.24 \pm 5.75$ & -0.289 & -1.544 & 0.141 & 0.135 \\
\hline Body image concern & 22 & 61 & $39.23 \pm 14.28$ & -0.006 & -1.733 & 0.173 & 0.104 \\
\hline Self-esteem & 15 & 32 & $25.79 \pm 5.29$ & -0.790 & -0.572 & 0.291 & 0.076 \\
\hline
\end{tabular}

results of the Bootstrap method for examining indirect intermediate paths are presented in Table 5.

An underlying assumption of the proposed model of the present study was the existence of indirect paths. When the number of samples is not large, Bootstrap provides the most powerful and logical approach to achieve indirect effects. Bootstrap results are outlined in Table 5. In this method, if the upper and lower limits of this test are both positive or both negative and not zero, the indirect

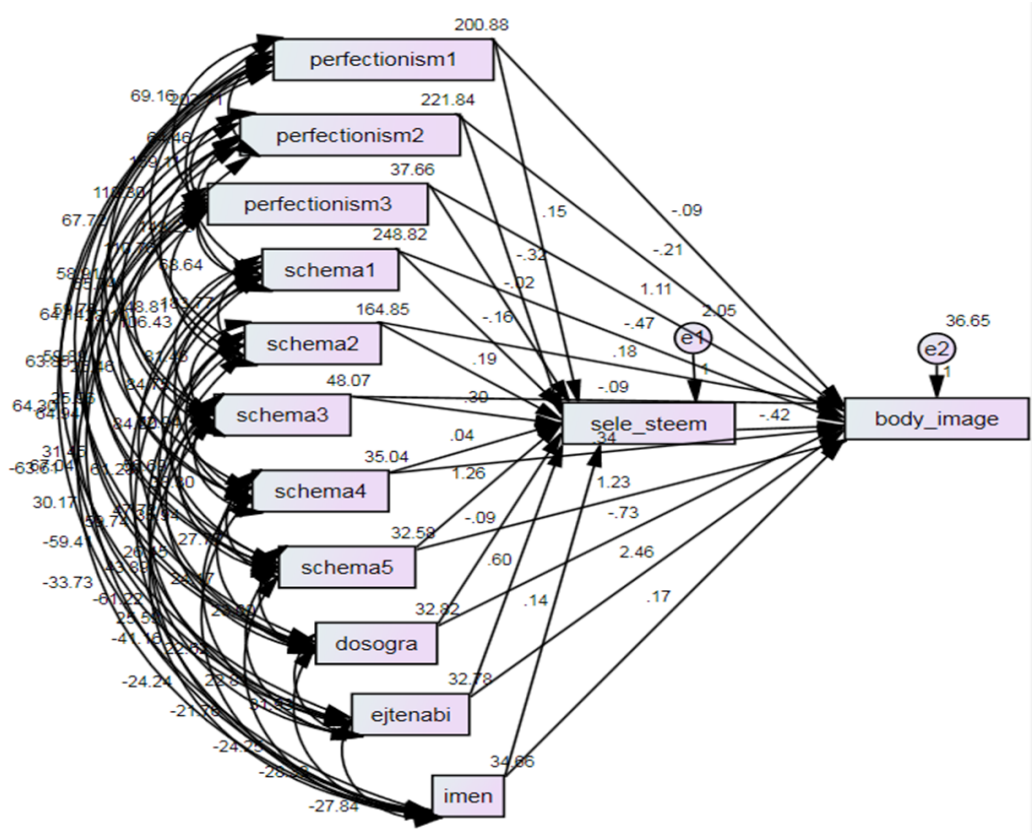

Figure 1. Proposed research model 
Table 3. Correlation matrix between the research variables

\begin{tabular}{|c|c|c|c|c|c|c|c|c|c|}
\hline Variables & 1 & 2 & 3 & 4 & 5 & 6 & 7 & 8 & 9 \\
\hline 1. Body image & 1 & & & & & & & & \\
\hline 2. Self-oriented & $0.684^{* *}$ & 1 & & & & & & & \\
\hline 3. Other-oriented & $0.652^{* *}$ & $0.760^{* *}$ & 1 & & & & & & \\
\hline 4. Social-oriented & $0.843^{* *}$ & $0.794^{* *}$ & $0.703^{* *}$ & 1 & & & & & \\
\hline 5. Schemas & $0.610^{* *}$ & $0.713^{* *}$ & $0.656^{* *}$ & $0.704^{* *}$ & 1 & & & & \\
\hline 6. Secure attachment & $-0.798^{* *}$ & $-0.761^{* *}$ & $-0.675^{* *}$ & $-0.733^{* *}$ & $-0.642^{* *}$ & 1 & & & \\
\hline 7. Anxious attachment & $0.874^{* *}$ & $0.786^{* *}$ & $0.761^{* *}$ & $0.895^{* *}$ & $0.699^{* *}$ & $-0.839^{* *}$ & 1 & & \\
\hline 8. Avoidant attachment & $0.880^{* *}$ & $0.792^{*}$ & $0.786^{* *}$ & $0.859^{* *}$ & $0.669^{* *}$ & $-0.825^{*}$ & $0.774^{* *}$ & 1 & \\
\hline 9. Self-esteem & $-0.658^{* *}$ & $-0.415^{*}$ & $-0.500^{* *}$ & $-0.715^{* *}$ & $-0.815^{* *}$ & $0.687^{* *}$ & $-0.717^{* *}$ & $-0.402^{*}$ & 1 \\
\hline
\end{tabular}

causal path will be significant. According to Table 5, this rule on the dimensions of perfectionism, early maladaptive schemas (only in the case of disconnection/rejection and hypervigilance) and attachment styles (only in the case of avoidant insecure attachment style) on body image concern applies with a mediating role of self-esteem.

To test the model in the present study, the Structural Equation Modeling (SEM) method was applied. To evaluate the suitability of the model, the indicators listed in Table 6 were used. Furthermore, if the Normalized Fit (NFI), Non-Normalized Fit (NNFI), Comparative Fit (CFI), Incremental
Fit (IFI), Goodness of Fit (GFI), and Adjusted or Adaptive Goodness of Fit (AGFI) indices are $>0.90$ and Parsimony Comparative Fit (PCFI) and Parsimonious Normed Fit (PNFI) are $>0.60$, a suitable and desirable fit of the model is established. As per Table 6, the proposed model failed to provide a suitable fit (RMSEA $=0.578$ ). For this purpose, the proposed correction model and non-significant paths were removed from the model. In the modified model of the research, the value of the Fitness Approximation Index (PCLOSE) was equal to 0.001 and the RMSEA index equaled 0.061 , which indicated the model fit according to Kline's model (2016). Therefore, considering that to have a

Table 4. The direct path coefficients of perfectionism, early maladaptive schemas, and attachment styles on body image concern

\begin{tabular}{|c|c|c|c|c|}
\hline Direct Paths & Beta Coefficient $(\boldsymbol{\beta})$ & Standard Error (SE) & Critical Ratio (CR) & $\mathbf{P}$ \\
\hline Self-oriented $\leftarrow$ body image concern & 0.086 & 0.258 & 0.332 & 0.740 \\
\hline Other-oriented $\leftarrow$ body image concern & 0.207 & 0.254 & 0.817 & 0.414 \\
\hline Society-oriented $\leftarrow$ body image concern & 0.829 & 0.217 & 3.827 & 0.001 \\
\hline Disconnection and rejection $\leftarrow$ body image & 0.196 & 0.175 & 2.272 & 0.014 \\
\hline Impaired function $\leftarrow$ body image & 0.182 & 0.262 & 0.694 & 0.488 \\
\hline Impaired body image limitations & 0.344 & 0.550 & 60.26 & 0.531 \\
\hline Self-direction $\leftarrow$ body image & 0.090 & 0.549 & 0.164 & 0.869 \\
\hline Hypervigilance $\leftarrow$ body image & 0.232 & 0.693 & 2.779 & 0.025 \\
\hline Secure attachment $\leftarrow$ body image & $0.168-$ & 0.324 & 0.518 & 0.604 \\
\hline Anxious attachment $\leftarrow$ body image & 0.730 & 0.665 & 1.097 & 0.273 \\
\hline Avoidance attachment $\leftarrow$ body image & 0.458 & 0.222 & 6.554 & 0.001 \\
\hline
\end{tabular}


Table 5. The bootstrap results of perfectionism, maladaptive schemas, and attachment concerning body image concern with the mediating role of self-esteem

\begin{tabular}{|c|c|c|c|}
\hline \multirow{2}{*}{ Indirect Routes } & \multicolumn{2}{|c|}{ Confidence Level 0.95} & \multirow{2}{*}{$\mathbf{P}$} \\
\hline & Lower Limit & Upper Limit & \\
\hline Self-oriented $\leftarrow$ self-esteem $\leftarrow$ body image concern & -0.217 & -0.056 & 0.015 \\
\hline Other-oriented $\leftarrow$ self-esteem $\leftarrow$ body image concern & -0.136 & -0.443 & 0.013 \\
\hline Society-oriented $\leftarrow$ self-esteem $\leftarrow$ body image concern & -0.044 & -0.130 & 0.027 \\
\hline Disconnection and rejection $\leftarrow$ self esteem $\leftarrow$ body image & -0.035 & -0.319 & 0.021 \\
\hline Impaired function $\leftarrow$ self-esteem $\leftarrow$ body image & -0.230 & 0.044 & 0.198 \\
\hline Impaired limitations $\leftarrow$ self-esteem $\leftarrow$ body image & -0.065 & 0.214 & 0.278 \\
\hline Self-esteem $\leftarrow$ self esteem $\leftarrow$ body image & -0.109 & 0.044 & 0.652 \\
\hline Listen to the ring $\leftarrow$ self-esteem $\leftarrow$ body image & -0.695 & -0.182 & 0.029 \\
\hline Secure attachment $\leftarrow$ self-esteem $\leftarrow$ body image & -0.116 & 0.011 & 0.182 \\
\hline Anxious attachment $\leftarrow$ self-esteem $\leftarrow$ body image & -0.226 & 0.051 & 0.121 \\
\hline Avoidant attachment $\leftarrow$ self-esteem $\leftarrow$ body image & -0.367 & -0.080 & 0.010 \\
\hline
\end{tabular}

favorable fit with body image concern, the model of perfectionism, early maladaptive schemas, and attachment styles the mediating role of self-esteem should be addressed, the research hypothesis was confirmed. The modified model is shown in Figure 2.

\section{Discussion}

The present study investigated the relationship between perfectionism, early maladaptive schemas, attachment styles, and body image concern through the mediating role of self-esteem in cosmetic surgery applicants. The relevant results indicated that only the direct path coefficient of self-oriented perfectionism was significant on body image concern. This result was consistent with those of Jamshidi and Hashemi (2019), as well as Saravani and Shirazi (2018). Explaining this result according to Higgins's (1989) Self-Discrepancy Theory (SDT), suggests that individuals compare their real selves with ideal standards or criteria (embodying the attitudes they want to achieve) (Gürcan Yildirim \& Gençöz 2020). According to SDT, if there is a discrepancy between the perception of who we are (the real body image) and our ideal view, we will feel dissatisfied and frustrated (Higgins 1989). Therefore, perfectionists, especially those with social-oriented perfectionism, believe that they must have a perfect performance, i.e. approved by the society; if their performance is below perfect, it makes them anxious and dissatisfied (Saravani \& Shirazi 2018).

Accordingly, these characteristics also affect their assessment of the physical condition and facial appearance; thus, it causes them to worry about their body image and demand for cosmetic surgery. Furthermore, society-oriented perfectionism involves the effort of an individual to achieve the criteria or standards and expectations prescribed by other members of society, such as family members, friends, acquaintances, and colleagues. This approach aims to provide self-sense, along with the fear of being evaluated, and insignificant and unwholesome effort to be perfect (Golestani, Aminbidokhti \& Jafari 2018). In such a perfectionism, i.e. the society-oriented, one believes that others and society expect them to be perfect or complete; thus, such conditions provide a basis in the individual for cosmetic surgery. Women perceive cosmetic surgery as an approach to reach the standards and criteria approved and expected by others; accordingly, their demand for cosmetic surgery increases. Therefore, it is logical that perfectionism, especially the society-oriented type directly impacts body image concern (Barnett \& Sharp 2016).

The obtained results revealed that only the direct path coefficient of disconnection and rejection and hypervigilance domains were significant on body image concern. 


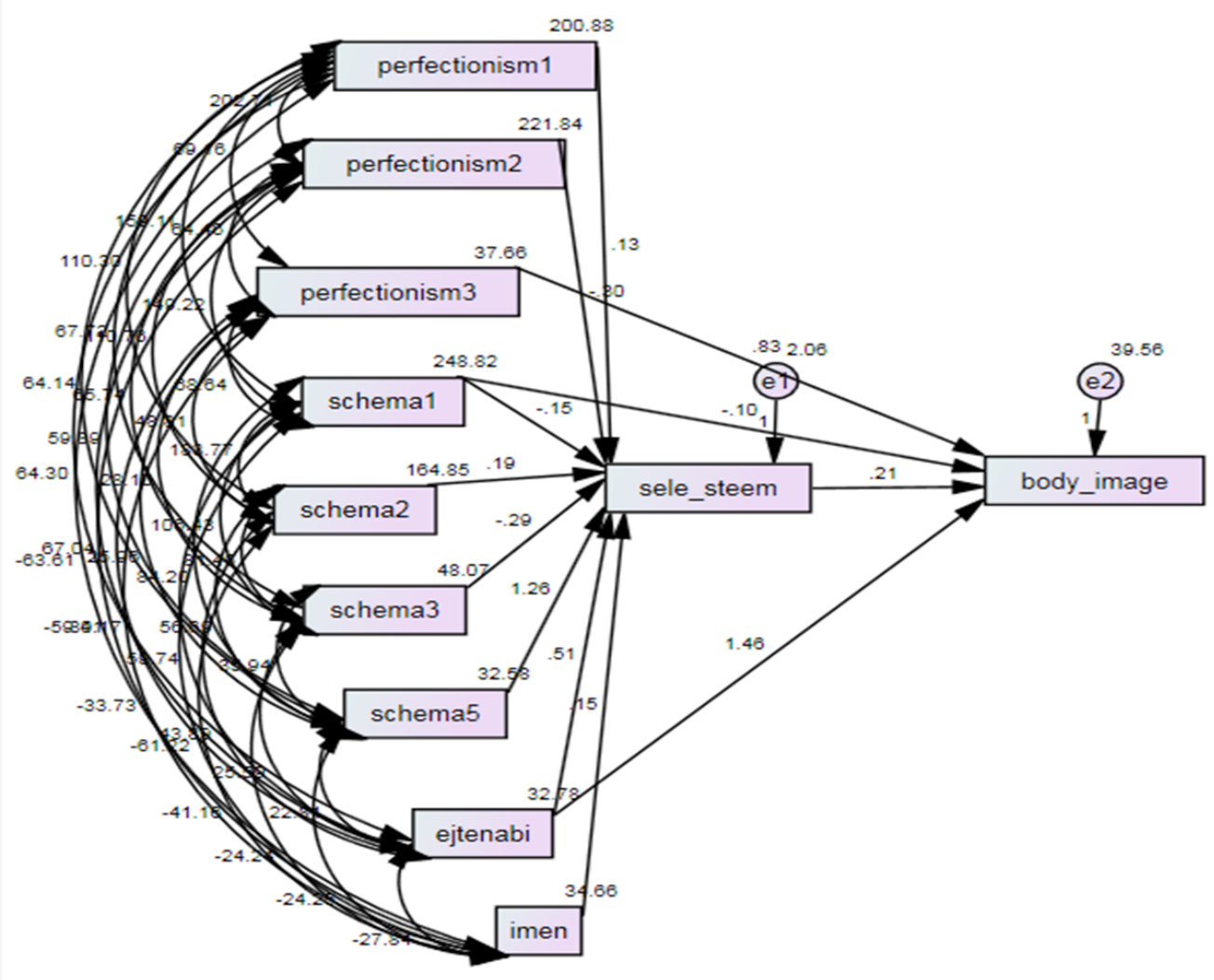

Figure 2. The modified research model

Client- Centered Nursing Care

This result is consistent with those of Ahmadi et al. (2020), Salehi et al. (2019), and Esmaeilnia, Dousti and Mirzaeian (2018). Such findings highlighted that numerous women with body image concerns are ashamed of their appearance and are worried that they will be judged by others. Therefore, these individuals have a strong tendency to use cosmetic surgery to relieve concerns about their body image; an essential relevant factor is the initial maladaptive schemas (Esmaeilnia et al. 2018).

An incompatible schema concerning rejection and disconnection is the rejection/abandonment type (Kizilagac \& Cerit 2019). Individuals with this schema expect to lose the loved ones and believe that individuals close to them will eventually get sick, die, leave them for someone else, and act unpredictably. This group feels that significant others in their lives cannot give them the emotional support and encouragement they need, because they are emotionally unstable and unpredictable. Therefore, they always live in a state of fear and anxiety, and chronic depression is a common emotion in the face of real or imagined loss in them (Young et al. 2003). Besides, literature indicated that depression is a crucial factor in the body image concern of individuals, especially women (Xie et al. 2010; Dean et al. 2020). Based on prior research, the existence of early maladaptive sche- mas respecting disconnection and rejection causes body image concern in women (Ahmadi et al. 2020).

The obtained data demonstrated that only the coefficient of direct avoidance attachment path was significant on body image concern. This result was consistent with those of Salehi et al. (2019), Homan et al. (2018), Szalai et al. (2017), and Davis and Vernon (2002). Khorshidi and Fathi Aqdam (2018) argued that among the types of attachment styles (safe, avoidant, and ambivalent), those with secure attachment styles present a better body image. Besides, students with avoidant and ambivalent attachment styles lack a favorable body image. Insecure attachment style leads to a strong search for approval from others and worries about gaining or maintaining the love of significant others. These concerns lead to employing various methods to maintain positive attention, including cosmetic surgery to enhance physical beauty. Therefore, it is logical to conclude that attachment styles, especially avoidant types, directly influence body image concerns in cosmetic surgery applicants.

The results of indirect coefficients also indicated that the indirect effects of the dimensions of perfectionism on body image concern with the mediating role of selfesteem were significant. This finding was consistent 
Table 6. The indicators of research model fitness

\begin{tabular}{|c|c|c|c|}
\hline \multicolumn{4}{|c|}{ Proposed Research Model (Before Modification) } \\
\hline Index Type & Indicators & Obtained Amount & Acceptable Amount \\
\hline \multirow{4}{*}{ Absolute indicators } & Chi-square $\mathrm{X}^{2}$ or CMIN & 2741.112 & \\
\hline & df & 78 & - \\
\hline & $P$ & 0.001 & - \\
\hline & Chi-square ratio to the degree of freedom $\mathrm{X}^{2} / \mathrm{df}$ or $\mathrm{CMIN} / \mathrm{df}$ & 2.142 & Less than 3 \\
\hline \multirow{9}{*}{ Relative indicators } & RMSEA & 0.578 & Less than 0.08 \\
\hline & PCLOSE & 0.001 & - \\
\hline & $\mathrm{CFI}$ & 0.985 & More than 0.90 \\
\hline & AGFI & 0.698 & More than 0.90 \\
\hline & PCFI & 0.001 & More than 0.60 \\
\hline & PNFI & 0.001 & More than 0.60 \\
\hline & IFI & 0.986 & More than 0.90 \\
\hline & GFI & 0.765 & More than 0.90 \\
\hline & $\mathrm{NFI}$ & 0.964 & More than 0.90 \\
\hline \multicolumn{4}{|c|}{ Modified Research Model } \\
\hline Index Type & Indicators & Obtained Amount & Acceptable Amount \\
\hline \multirow{4}{*}{ Absolute indicators } & Chi-square $\mathrm{X}^{2}$ or CMIN & 2044.035 & \\
\hline & df & 55 & - \\
\hline & $\mathrm{P}$ & 0.0001 & - \\
\hline & Chi-square ratio to the degree of freedom $\mathrm{X}^{2} / \mathrm{df}$ or $\mathrm{CMIN} / \mathrm{df}$ & 2.164 & Less than 3 \\
\hline \multirow{9}{*}{ Relative indicators } & RMSEA & 0.061 & Less than 0.08 \\
\hline & PCLOSE & 0.001 & - \\
\hline & CFI & 0.981 & More than 0.90 \\
\hline & AGFI & 0.997 & More than 0.90 \\
\hline & PCFI & 0.727 & More than 0.60 \\
\hline & PNFI & 0.627 & More than 0.60 \\
\hline & $\mathrm{IFI}$ & 0.987 & More than 0.90 \\
\hline & GFI & 0.989 & More than 0.90 \\
\hline & $\mathrm{NFI}$ & 0.997 & More than 0.90 \\
\hline
\end{tabular}

RMSEA: Root Mean Square Error of Approximation; CFI: Comparative Fit Index; AGFI: Adjusted Goodness of Fit Index; PCFI: Parsimonious Comparative Fit Index; PNFI: Parsimony Normed Fit Index; IFI: Incremental Fit Index; GFI: Goodness of Fit Index; NFI: Normed Fit Index. 
with those of Jamshidi and Hashemi (2019), Yoon and Kim (2020), as well as Ghanbari Nejad Esfahan Sari and Zarbakhsh Bahri (2015). In other words, perfectionism is a constant source of stress that often leaves a person with failure. Perfectionists commit themselves to perfection (Hewitt et al. 2020). In self-oriented perfectionism, there is a set of ideal criteria and standards that an individual adopts and sets for himself, and his/ her motivation is to be perfect and flawless. Therefore, in this type of perfectionism, an individual believes that he/she must be perfect; subsequently, they consider irrational standards for themselves and impose these standards on themselves (Kannis-Dymand et al. 2020). The higher the perfectionism and ambitious expectations, regardless of the individual's abilities, the more depression is experienced (Jamshidi \& Hashemi 2019). In this regard, perfectionism can play an important role in the self-esteem of individuals seeking cosmetic surgery. Individuals with low self-esteem are constantly seeking the approval of others. Accordingly, to obtain this approval, they apply for cosmetic surgery to reduce their body image concern. Thus, self-esteem is indirectly related to self-oriented perfectionism and body image concern.

The indirect coefficients data also signified that the indirect effects of early maladaptive schemas (only in the case of disconnection/rejection domain and hypervigilance domain) on body image concern the mediating role of self-esteem, i.e. significant. This result was consistent with those of Yoon and Kim (2020), Ghanbari Nejad Esfaqan Sari and Zarbakhsh Bahri (2015), and Salehi et al. (2019). In other words, when self-esteem is declined due to the presence of early maladaptive schemas, problems, like body image concern will emerge. Self-esteem is directly related to the physical aspects of individuals, such as appearance, beauty, and physical disability; it causes judgments about self and includes the desired goals of the individual and his/her aspirations. These objectives are the same as individual values (Brechan \& Kvalem 2015). Self-esteem is strongly associated with body image concern and its related coping style. Thus, a positive body image creates a sense of worth. In return, negative body image and the fear that it has been changed in any way leads to the same level of alternation in self-esteem. Therefore, self-esteem is indirectly related to body image concern respecting early maladaptive schemas (disconnection/rejection and hypervigilance).

The results of indirect coefficients also presented that the indirect effects of attachment styles (avoidance style only) on body image concern, with the mediating role of selfesteem, were significant. This result was in line with those of Salehi et al. (2019), Yoon and Kim (2020), Ghanbari
Nejad Esfaqan Sari and Zarbakhsh Bahri (2015), Homan et al. (2018), Szalai et al. (2017), and Davis and Vernon (2002). As a result, attachment is a deep emotional bond, i.e. established with certain individuals in life; it enables individuals to enjoy interacting with them and feel close to them in times of stress (Attaran \& Mohammadi 2018). Among attachment styles, the insecure avoidance style plays an essential role in decreasing the level of self-esteem of individuals. When a subject experiences declined self-esteem due to negative practical models and avoidant attachment, their body image concern rises; consequently, low self-esteem was reported to be associated with body image concern (Cash \& Fleming 2002).

\section{Conclusion}

According to the present study design, the obtained relationships can not be interpreted as cause-and-effect patterns. To further generalize the results, it is suggested that students and researchers repeat such research in other cities to provide evidence of the obtained relationships. It is suggested that the present research model be examined based on other variables, such as personality traits, coping styles, and coping schemas.

The achievements and consequences of this research can be presented at theoretical and practical levels. At the theoretical level, the research findings can help to expand the knowledge, concepts, and models concerning body image concern in cosmetic surgery applicants. This could be achieved by explaining perfectionism, early maladaptive schemas, and attachment styles. Additionally, the present study data can facilitate newer research to expand psychological knowledge regarding factors affecting the formation of body image concerns in applicants for cosmetic surgery. At the practical level, the current research findings can be used to develop treatment programs and interventions, such as training based on attachment style, and schema therapy in relevant organizations, such as counseling centers and psychological services, and so on. Such measures could help to improve body image concern in women; thus, clinical psychologists, counselors, and psychiatric nurses can use the results of this research.

\section{Ethical Considerations}

\section{Compliance with ethical guidelines}

The study was approved by the Ethics Committee of Islamic Azad University, Roudehen Branch (Code: 162370017). All ethical principles are considered in this article. The participants were informed about the 
purpose of the research and its implementation stages. They were also assured about the confidentiality of their information and were free to leave the study whenever they wished, and if desired, the research results would be available to them.

\section{Funding}

The present paper was extracted from the $\mathrm{PhD}$ dissertation of the first author at the Department of Psychology, Roudehen Branch, Islamic Azad University.

\section{Authors' contributions}

Conceptualization and supervision: Fatemeh Moghadam, Hossein Ebrahimi Moghadam; Methodology: Fatemeh Moghadam, Pantea Jahangir; Investigation, writing-review \& editing: All authors. Writing original draft: Hossein Ebrahimi Moghadam, Fatemeh Moghadam, Pantea Jahangir.

\section{Conflict of interest}

The authors declared no conflicts of interest.

\section{Acknowledgments}

All authors would like to thank all the individuals who participated in the study and the staff and faculty members of the Department of Psychology, Islamic Azad University, Roudehen Branch.

\section{References}

Ahmadi, A., et al., 2020. [Predicting the body image concern based on early maladaptive schemas and attachment styles (Persian)]. Scientific Journal of Educational Research, 15(63). http://edu.bojnourdiau.ac.ir/article_673771.html?lang=en

Askari, M., \& Ramezani Badr, F., 2015. [A comparative study of body image concern and self esteem among male and female students of Abhar Islamic Azad University (Persian)]. Behavioral Sciences Quarterly, 1(1), pp. 165-49. https:/ / www.magiran. $\mathrm{com} /$ paper $/ 1825637$

Attaran, N., \& Mohammadi, N., 2018. [The mediating role of self esteem in the relationship between attachment orientations and psychological adjustment (Persian)]. Journal of Developmental Psychology (Iranian Psychologists), 15(58), pp. 151-39. http://jip.azad.ac.ir/article_664387.html

Barnes, M., et al., 2020. Associations between body dissatisfaction and self-reported anxiety and depression in otherwise healthy men: A systematic review and meta-analysis. PloS
One, 15(2), p. e0229268. [DOI:10.1371/journal.pone.0229268] [PMID] [PMCID]

Barnett, M. D., \& Sharp, K. J., 2016. Maladaptive perfectionism, body image satisfaction, and disordered eating behaviors among U.S. college women: The mediating role of self-compassion. Personality and Individual Differences, 99, pp. 225-34. [DOI:10.1016/j.paid.2016.05.004]

Borges, J. L., \& Dell'Aglio, D. D., 2020. Early maladaptive schemas as mediators between child maltreatment and dating violence in adolescence. Ciência \& Saúde Coletiva, 25(1), pp. 3119-30. [DOI:10.1590/1413-81232020258.24992018] [PMID]

Borji, M., et al., 2019. [Predicting suicidal ideation based on life meaning and early maladaptive schemas in students (Persian)]. Journal of Social Health, 6(2), pp. 196-207. [DOI:10.22037/ ch.v6i2.21960]

Brechan, I., \& Kvalem, I. L., 2015. Relationship between body dissatisfaction and disordered eating: Mediating role of self-esteem and depression. Eating Behaviors, 17, pp. 49-58 [DOI:10.1016/j.eatbeh.2014.12.008] [PMID]

Carrard, I., Rothen, S., \& Rodgers, R. F., 2020. Body image and disordered eating in older women: A Tripartite Sociocultura model. Eating Behaviors, 38, p.101412 [DOI:10.1016/j.eatbeh.2020.101412] [PMID]

Cash, T. F., \& Fleming, E. C., 2002. The impact of body image experiences: Development of the body image quality of life inventory. International Journal of Eating Disorders, 31(4), pp. 455-60. [DOI:10.1002/eat.10033] [PMID]

Chen, C., et al., 2019. Multidimensional perfectionism and borderline personality organization in emerging adults: A twowave longitudinal study. Personality and Individual Differences, 146, pp. 143-8. [DOI:10.1016/j.paid.2019.04.011]

Collins, N. R., \& Read, S. J., 1990. Adult attachment, working models, and relationship quality in dating couples. Journal of Personality and Social Psychology, 58(4), pp. 644-63. [DOI:10.1037/0022-3514.58.4.644]

Conner, K. M., \& Davidson, J, R., 2003. Development of a new resilience scale. Depression and Anxiety, 18(2), pp. 76-82. [DOI:10.1002/da.10113] [PMID]

Costa, P. T. Jr., \& McCrae, R. R., 2008. The Revised NEO Personality Inventory (NEO-PI-R). In: G. J. Boyle., G. Matthews \& D. H. Saklofske (eds), The SAGE handbook of personality theory and assessment, Sage Publications, Inc, London. [DOI:10.4135/9781849200479.n9]

Cudo, A., et al., 2020. The role of depression and self-esteem in Facebook intrusion and gaming disorder among young adult gamers. Psychiatric Quarterly, 91(1), pp. 65-76. [DOI:10.1007/ s11126-019-09685-6] [PMID]

Curran, T., \& Hill, A. P., 2019. Perfectionism is increasing over time: A meta-analysis of birth cohort differences from 1989 to 2016. Psychological Bulletin, 145(4), pp. 410-29. [DOI:10.1037/ bul0000138] [PMID]

Davis, D., \& Vernon, M. L., 2002. Sculpting the body beautiful: Attachment style, neuroticism, and use of cosmetic surgeries Sex Roles, 47(3-4), pp. 129-38. [DOI:10.1023/ A:1021043021624]

Dean, E., et al., 2020. Body image in older, inpatient women and the relationship to BMI, anxiety, depression, and other soci- 
odemographic factors. International Journal of Geriatric Psychiatry, 35(2), pp. 182-7. [DOI:10.1002/gps.5233] [PMID]

Dehghan, M., et al., 2015. Effect of kangaroo mother care on the self-esteem of mothers of preterm infants hospitalized in the neonatal intensive care unit. Journal of Client-centered Nursing Care, 1(4), pp. 177-82. [DOI:10.15412/J.JCCNC.04010402]

E'temadifard, S., \& Amani, M., 2013. [A Sociological study on women's motivations for pursuing cosmetic surgery (Persian)]. Women Studies, 4(8), pp. 1-22. http:/ / womenstudy.ihcs. ac.ir/article_1069.html?lang=en

Enayat, H., \& Anbari Roozbehani, M., 2017. [Investigating the psychological causes of women's tendency to cosmetic surgery (Case study: Women aged 15-50 years in Shiraz) (Persian)]. Journal of Alborz University of Medical Sciences, 7(1), pp. 24-34. [DOI:10.29252/aums.7.1.24]

Fuchshuber, J., et al., 2019. The influence of attachment styles and personality organization on emotional functioning after childhood trauma. Frontiers in Psychiatry, 10(1), pp. 643-51. [DOI:10.3389/fpsyt.2019.00643] [PMID] [PMCID]

García, J. A., et al., 2019. Self-esteem levels vs global scores on the Rosenberg self-esteem scale. Heliyon, 5(3), pp. 1378-86. [DOI:10.1016/j.heliyon.2019.e01378] [PMID] [PMCID]

Ghanbari Nejad Esfahan Sari, M., \& Zarbakhsh Bahri, M. R., 2015. [Investigating the relationship between self-esteem and dysfunctional attitudes with body image concerns in rhinoplasty applicants (Persain)]. Paper Presented at the 1st International Conference on Psychology and Educational Sciences, Shiraz, Iran, 12 October 2015. https://civilica.com/ doc/460169/

Gillen, M. M., \& Markey, C. H., 2020. Body image, weight management behavior, and women's interest in cosmetic surgery. Psychology, Health \& Medicine, 1(1), pp. 1-10. [DOI:10.1080/135 48506.2020.1776890] [PMID]

Golestani, H., Aminbidokhti, A. A., \& Jafari, S., 2018. [The relationship between selfish and community-oriented perfectionism and academic burnout due to the mediating role of internal and external motivation (Persian)]. Journal of Clinical Psychology, 10(1), pp. 89-79. [DOI:10.22075/JCP.2018.10752.1038]

Gouin, J. P., \& MacNeil, S., 2019. Attachment style and changes in systemic inflammation following migration to a new country among international students. Attachment \& Human Development, 21(1), pp. 38-56. [DOI:10.1080/14616734.2018.1541515 ] [PMID]

Gürcan-Yıldırım, D., \& Gençöz, T., 2020. The association of selfdiscrepancy with depression and anxiety: Moderator roles of emotion regulation and resilience. Current Psychology, pp. 1-14. [DOI:10.1007/s12144-020-00701-8]

Harorani, M., et al., 2018. Relationship between self-efficacy and self-esteem in patients with cancer. Journal of Client-centered Nursing Care, 4(1), pp. 45-52. [DOI:10.32598/jccnc.4.1.45]

Hejazi, A., \& Hashemi, S., 2020. [Emotional fatigue based on the dimensions of perfectionism and teachers' emotions (Persian)]. Journal of Research in Educational Systems, 14(48), pp. 14560. [DOI:10.22034/JIERA.2020.173494.1819]

Henschel, S., Nandrino, J. L., \& Doba, K., 2020. Emotion regulation and empathic abilities in young adults: The role of attachment styles. Personality and Individual Differences, 156(1), pp. 109-23. [DOI:10.1016/j.paid.2019.109763]
Hewitt, P. L., \& Flett, G. L., 1991. Perfectionism in the self and social contexts: Conceptualization, assessment, and association with psychopathology. Journal of Personality and Social Psychology, 60(3), pp. 456-70. [DOI:10.1037/0022-3514.60.3.456] [PMID]

Hewitt, P. L., et al., 2020. The perniciousness of perfectionism in group therapy for depression: A test of the perfectionism social disconnection model. Psychotherapy, 1(1), pp. 1-43. [DOI:10.1037/pst0000281] [PMID]

Heidari, M., et al., 2016. [An analytical study of body image concern and aggression in male and female high school students (Persian)]. Journal of Urmia Nursing and Midwifery, 14 (10), pp. 837-46. http:// unmf.umsu.ac.ir/article-1-2952-en.html

Higgins, E. T., 1989. Self-discrepancy theory: What patterns of self-beliefs cause people to suffer? Advances in Experimental Social Psychology, 22, pp. 93-136. [DOI:10.1016/S00652601(08)60306-8]

Homan, K. J., et al., 2018. Don't bring me down effects of priming secure and anxious attachment on body image. Journal of Social and Personal Relationships, 35(7), pp. 936-55. [DOI:10.1177/0265407517701298]

Esmaeilnia, M. R., Dousti, Y. A., \& Mirzaeian, B., 2018. [Structural relationships between early maladaptive schemas and body dysmorphic disorder mediated by anxiety and anxiety (Persian)]. Journal of Social Health, 6(1), pp. 80-9. [DOI:10.22037/ ch.v6i1.23611]

Jamshidi, M., \& Hashemi, S., 2019. [The relationship between perfectionism and depression with body image in girls volunteering for cosmetic surgery (Persian)]. Journal of Dermatology and Cosmetic, 10(1), pp. 11-3. https://jdc.tums.ac.ir/article1-5367-fa.html

Janovsky, T., et al., 2020. The relationship between early maladaptive schemas and interpersonal problems: A meta-analytic review. Clinical Psychology \& Psychotherapy, 27(3), pp. 408-47. [DOI:10.1002/cpp.2439] [PMID]

Kannis-Dymand, L., et al., 2020. Examining the roles of metacognitive beliefs and maladaptive aspects of perfectionism in depression and anxiety. Behavioural and Cognitive Psychotherapy, 48(4), pp. 442-53. [DOI:10.1017/S1352465820000144] [PMID]

Karazsia, B. T., Murnen, S. K., \& Tylka, T. L., 2017. Is body dissatisfaction changing across time? A cross-temporal meta-analysis. Psychological Bulletin, 143(3), pp. 293-320. [DOI:10.1037/ bul0000081] [PMID]

Kizilagac, F., \& Cerit, C., 2019. Assessment of early maladaptive schemas in patients with Obsessive-Compulsive Disorder. $\mathrm{Du}$ sunen Adam The Journal of Psychiatry and Neurological Sciences, 32, pp. 14-22. https://doi.org/10.14744/DAJPNS.2019.00003

Khorshidi, F., \& Fathi Aqdam, G., 2018. [Relationship between general self-efficacy and attachment styles with female students' body image (Persian)]. Journal of Psychiatric Nursing, 6(1), pp. 26-34. http://ijpn.ir/article-1-1052-en.html

Kline, R. B., 2016. Principles and practice of structural equation modeling. The Guilford Press, New York. https://books. google.com $/$ books?id=Q61ECgAAQBAJ\&printsec $=$ frontcov er\&dq

Koppers, D., et al., 2020. Psychological symptoms, early maladaptive schemas and schema modes: Predictors of the outcome of group schema therapy in patients with personality 
disorders. Psychotherapy Research, pp. 1-12. [DOI:10.1080/1050 3307.2020.1852482] [PMID]

Lannoy, S., et al., 2020. Too good to be cautious: High implicit self-esteem predicts self-reported dangerous mobile phone use. Computers in Human Behavior, 103(1), pp. 208-13. [DOI:10.1016/j.chb.2019.09.018]

Lazuka, R. F., et al., 2020. Are we there yet? Progress in depicting diverse images of beauty in instagram's body positivity movement. Body Image, 34(1), pp. 85-93. [DOI:10.1016/j.bodyim.2020.05.001] [PMID]

Littleton, H. L., Axsom, D., \& Pury, C. L., 2005. Development of the body image concern inventory. Behaviour Research and Therapy, 43(2), pp. 229-41. [DOI:10.1016/j.brat.2003.12.006] [PMID]

Meneguzzo, P., et al., 2020. The predictive value of the early maladaptive schemas in social situations in anorexia nervosa. European Eating Disorders Review, 28(3), pp. 318-31. [DOI:10.1002/ erv.2724] [PMID]

Nasiri, F., Nasiri, S., \& Bakhshi Pour Rudsari, A., 2014. [Predicting substance use tendencies based on self esteem and emotional intelligence components (Persian)]. Scientific Quarterly Research on Addiction, 8(31), pp. 135-46. http:/ / etiadpajohi.ir/ article-1-65-fa.html

Nilforoshan, P., Navidian, A., \& Shamhammdi, M., 2015. [Early maladaptive schemas and general health in women seeking cosmetic surgery (Persian)]. Iranian Journal of Psychiatric Nursing, 3(1), pp. 12-23. http://ijpn.ir/browse.php?a_code=A-10$1-48 \&$ slc_lang $=$ fa\&sid $=1$

Preacher, K. J., \& Hayes, A. F., 2004. SPSS and SAS procedures for estimating indirect effects in simple mediation models. Behavior Research Methods, Instrument \& Computers, 36(4), pp. 717-31. [DOI:10.3758/BF03206553] [PMID]

Rezaei Jamaloui, H., Hassani J., \& Normohamadi Najafabadi, M., 2019. [The role of attachment styles in high-risk behaviors of secondary school boys (Persian)]. Journal of Knowledge and Research in Applied Psychology, 20(1), pp. 112-21. [DOI:10.30486/ JSRP.2019.663551]

Rosenthal, S. A., et al., 2020. The narcissistic grandiosity scale: A measure to distinguish narcissistic grandiosity from high self-esteem. Assessment, 27(3), pp. 487-507. [DOI:10.1177/1073191119858410] [PMID]

Rounagh Sheshkelani, M., et al., 2018. [Comparison of body image and life satisfaction in applicants cosmetic and those surgical operated of oral and maxillofacial and cosmetic surgery part at the education and health care of Imam Reza Hospital in Tabriz (Persina)]. Razi Journal of Medical Sciences, 25(8), pp. 12-23. http://rjms.iums.ac.ir/browse.php?a id $=5067 \&$ sid $=1 \&$ slc_lang=fa

Sadeghi, M., et al., 2019. [Developing a causal model of the relationship between academic perfectionism and academic procrastination of medical students: With the mediating role of emotional self-awareness (Persian)]. Teaching Strategies in Medical Sciences, 12(2), 80-8. http://edcbmj.ir/article1-1502-fa.html

Salehi, M., Rajabi, S., \& Dehghani, Y., 2019. [Predicting body deformity disorder based on emotional schemas, attachment styles and personality traits in people seeking cosmetic surgery (Persian)]. Journal of Psychologicalscience, 18(73), pp. 77-87. https:/ / psychologicalscience.ir/article-1-175-en.html
Salmanpour, H., et al., 2014. [The relationship between early maladaptive schemas and perfectionism: A test of a causal pattern (Persian)]. New Psychological Research, 9(35), pp. 81-97. https:// psychologyj.tabrizu.ac.ir/article_4024.htm

Saravani, S., \& Shirazi, M., 2018. [The role of obsessive beliefs and perfectionism in the body image of third grade female high school students in Zahedan (Persian)]. Journal of Educational Psychology Studies, 15(30), pp. 167-86. [DOI:10.22111/ JEPS.2018.3618]

Shabani Khadio, A., \& Ahmadian, H., 2019. [Studying the relationship between of Basic psychological needs satisfaction and the Emotional Regulation disorder with the mediation of early maladaptive schemas at Bu-AliSina university students (Persian)]. Knowledge and Research in Applied Psychology, 20(1) pp. 101-11. [DOI:10.30486/JSRP.2019.663548]

Sun, S., et al., 2020. Benefit-seeking or risk-taking? Examining the portrayal of cosmetic surgery in chinese news, 2000-2019. International Journal of Environmental Research and Public Health, 18(1), p. 48. https://doi.org/10.3390/ijerph18010048

Shirmohammadi, S., Hosseini, S., \& Amiri, H., 2020. [Structural equation modeling the relationship between psychopathology and attachment styles with mediation of the role of basic psychological needs in women applicants for cosmetic surgery in Kermanshah (Persian)]. Journal of Dermatology and Cosmetic, 11(2), pp. 119-30. https:/ /jdc.tums.ac.ir/article-1-5460-fa.html

Swami, V., et al., 2009. Acceptance of cosmetic surgery: Personality and individual difference predictors. Body Image, 6(1), pp. 7-13. [DOI:10.1016/j.bodyim.2008.09.004] [PMID]

Szalai, T. D., et al., 2017. Parental attachment and body satisfaction in adolescents. Journal of Child and Family Studies, 26(4) pp. 1007-17. [DOI:10.1007/s10826-016-0626-z]

Tam, C. C., Benotsch, E. G., \& Li, X., 2020. Self-esteem and nonmedical use of prescription drugs among college students: Coping as a mediator. Substance Use \& Misuse, 55(8), pp. 1309-19. [D OI:10.1080/10826084.2020.1735441] [PMID]

Thompson, K. A., \& Bardone-Cone, A. M., 2019. Evaluating attitudes about aging and body comparison as moderators of the relationship between menopausal status and disordered eating and body image concerns among middle-aged women. Maturitas, 124, pp. 25-31. [DOI:10.1016/j.maturitas.2019.03.014] [PMID]

Troncone, A., et al., 2020. Body image problems and disordered eating behaviors in Italian adolescents with and without type 1 diabetes: An examination with a gender-specific body image measure. Frontiers in Psychology, 11(1), pp. 254-7. [DOI:10.3389/fpsyg.2020.556520] [PMID] [PMCID]

Vaghar Hasanpur, M., Jalali, Y., \& Tayebli, M., 2020. [Modeling the relationship between the big five personality traits and resilience, considering self-esteem as a mediator variable (Persian)]. Shenakht Journal of Psychology and Psychiatry, 7(4), pp. 78-92 https://shenakht.muk.ac.ir/article-1-930-fa.html

Wells, A. E., et al., 2020. Low self-esteem and impairments in emotion recognition predict behavioural problems in children. Journal of Psychopathology and Behavioral Assessment, 42(1), pp. 693-701. [DOI:10.1007/s10862-020-09814-7]

Xie, B., et al., 2010. Overweight, body image, and depression in Asian and Hispanic adolescents. American Journal of Health Behavior, 34(4), pp. 476-88. [DOI:10.5993/AJHB.34.4.9] [PMID] [PMCID] 
Yektatalab, S., et al., 2015. Sexual dysfunction in breast cancer survivors. Journal of Client-centered Nursing Care, 1(1), pp. 9-14. http://jccnc.iums.ac.ir/browse.php?a_id=28\&sid=1\&slc_ lang=en

Yoon, S., \& Kim, Y. A., 2020. Cosmetic surgery and self-esteem in South Korea: A systematic review and meta-analysis. Aesthetic Plastic Surgery, 44(1), pp. 229-38. [DOI:10.1007/s00266019-01515-1] [PMID] [PMCID]

Young, J. E., \& Brown, G., 2005. Young Schema Questionnaire Short Form 3 (YSQ-S3). Cognitive Therapy Center, New York. [DOI:10.1037/t67023-000]

Young, J. E., Klosko, J. S., \& Weishaar, M. E., 2003. Schema therapy: A practitioner's guide. Guilford Press, New York.

Zeifman, R. J., Antony, M. M., \& Kuo, J. R., 2020. When being imperfect just won't do: Exploring the relationship between perfectionism, emotion dysregulation, and suicidal ideation. Personality and Individual Differences, 152(1), p. 109612. [DOI:10.1016/j.paid.2019.109612] 
This Page Intentionally Left Blank 